\title{
Evaluation of the Teaching Quality and Ability of Hospital Administrators by Overseas Distinguished Teachers
}

\author{
Zijian Wu ${ }^{1 s t, 1}$, Shaoxuan $\mathrm{Yu}^{1 \mathrm{st}, 2}$, Yihua $\mathrm{Li}^{3 *}$, Shaohan Chen ${ }^{1}$, Jia Wang ${ }^{1}$, Tiantian Cheng ${ }^{1}$ \\ ${ }^{1}$ Clinical Research Management Department, Affiliated Cancer Hospital \& Institute of Guangzhou Medical University, No.78, \\ Hengzhigang Road, Yuexiu District, Guangzhou, China.510095. \\ ${ }^{2}$ Guangzhou Medical University, Xinzao,Panyu District, Guangzhou, China,511436. \\ ${ }^{3}$ Hospital Office, Affiliated Cancer Hospital \& Institute of Guangzhou Medical University, No.78, Hengzhigang Road, Yuexiu District, \\ Guangzhou, China.510095. \\ Zijian Wu and ShaoxuanYu contribute equally
}

\begin{abstract}
In recent years, China has been actively promoting the Belt and Road Initiative. In the context of the gradual opening of the medical market, it is urgent to improve the health management knowledge and scientific research capabilities of the hospital administrators, further enhance the hospital management level, so that the hospitals can obtain a greater edge in the international medical competition. Using overseas intelligence to promote the internationalization of education is one of the important means. The Affiliated Cancer Hospital and Institute of Guangzhou Medical University has invited Portuguese management professors to establish an academic and educational cooperation relationship, and invited them to offer training for hospital administrators. This article uses questionnaires to survey the trainees participating in this training and evaluates the teaching quality of overseas teachers. The results showthat the interviewed students generally present high affirmation to the training effects of the training courses and the teaching quality of overseas distinguished teachers.
\end{abstract}

\section{Introduction}

In China, under the background of the rapid development of information technology and the policy background of the Belt and Road Initiative, the medical and health industry is gradually opening up to the world, which has ushered in opportunities for the development of Chinese hospitals and also brought challenges to hospital management[1-3]. Exchanges of China with the international community in the medical field have been increasing, and hospital management has presented the need to be in line with international standards. Medical administrators and health management must adopt a forward-looking arrangement in which scientific research thinking crosses the gap between China and the West, so that scientific research and innovation capabilities can be improved to meet international requirements, and this is inseparable from the special guidance of fellow international management scholars[4, 5]. Relevant research results show that inviting overseas distinguished scholars to promote international cooperative education will help domestic scholars to more conveniently experience foreign high-quality education and understand more advanced international scientific and technological achievements[6, 7]. Funded by the "Overseas Distinguished Teachers" project of Department of Science and Technology of Guangdong Province, the
Affiliated Cancer Hospital and Institute of Guangzhou Medical University has invited Portuguese management professors to offer health management special training for hospital administrators. This article uses questionnaires to survey the trainees participating in this training and evaluates the teaching quality of overseas teachers.

\section{Research background}

\subsection{China actively promotes international cooperative education}

With the continuous deepening of the global integration process, the trend of globalization has become an indisputable fact. In 2013, China put forward the concept of Belt and Road Initiative. China has been actively developing economic partnerships with many countries and jointly building a political, economic, and cultural community. To be specific, promoting the internationalization of education, strengthening the overseas study of talents, and the introduction of overseas talents and overseas intelligence are one of the important measures in the plan. On May 5, 2010, the Executive Meeting of the State Council of China reviewed and approved the National Mid-and-long-term Education Reform and Development Plan Outline (2010-2020) in which it was clearly stated to"explore

*Corresponding author Email address: lyhyys@21cn.com 
multiple ways to utilize foreign high-quality educational resources,attract more world-class experts and scholars to come to China for teaching, scientific research and management, and introduce overseas high-end talents and academic teams in a scheduled way”. In the $13^{\text {th }}$ Five-Year Development Plan of Shanghai, it was clearly stated that "training innovative and inter-disciplinary talents with an international vision" is one of the main development goals. It can be seen that the promotion of international cooperative education in China has risen to the key development strategy level for the country, provinces and cities[6].

\section{2. "Overseas Distinguished Teachers" Project}

In order to improve the quality of higher education and enhance the comprehensive competitiveness of universities, the Ministry of Education of China has launched the "Overseas Distinguished Teachers" Project in universities in major provinces of China since 2007, and supported universities to hire a group of international first-class teachers to teach and cooperate in scientific research in China. Based on this project, over the years, many universities in China have introduced a group of internationally recognized high-level expert scholars and teams, actively carried out international education cooperation, and advocated to organize high-level international academic conference, which not only broadens the international academic vision of faculty, staff and graduate students, but also lays the foundation for building a high-level academic platform[7, 8].

\section{Respondents and research research methods}

In October 2020, the author conducted a survey with the administrative staff of the Affiliated Cancer Hospital and Institute of Guangzhou Medical University to understand the basis of their health management research capabilities and their learning needs for related knowledge. The results showed that their scientific research knowledge base was average, but their learning needs and scientific research method base were relatively ideal. Different ages and educational levels had significant differences in the basis of scientific research knowledge, scientific research training needs, and scientific research methods. Under the funding of the 2020-2021 "Overseas Distinguished Teachers” Science and Technology Project of the Guangdong Provincial Department of Education, the Affiliated Cancer Hospital and Institute of Guangzhou Medical University invited the Portuguese management professor Virginia Trigo to carry out health management special training for the hospital administrators on December 14, 2020. This research will use questionnaires to survey the trainees participating in the training and evaluate the teaching quality.

\subsection{Research respondents and questionnaire collection process}

In this study, the Affiliated Cancer Hospital and Institute of Guangzhou Medical University was selected as the survey case. The respondents were administrative staff (age $\geq 18$ years old) of the hospital who participated in the special training on December 14, 2020[9]. The hospital is a tertiary first-class hospital in Guangzhou, Guangdong Province, China. The level of medical technology and influence is at the forefront in southern China. The scale was issued in the form of an electronic questionnaire.We have compiled an electronic version of the scale through the online questionnaire website (https://www.wjx.cn/). Respondents can obtain online questionnaires by scanning the QR code. After they complete the questionnaire survey, the data will be automatically saved and uploaded to the website server, after which the database can be exported through the server background.

\subsection{Scale design}

For the survey scale used in this research, we refer to the evaluation scale used in the 2014 First College Young Teacher Teaching Competition in Jiangxi Province, and modify the scale slightly as for the expression of items based on the training contents and the actual situation of the surveyed hospital[10]. We randomly selected 3 hospital administrators who met the inclusion criteria to conduct face-to-face informal interviews. The results of the interview showed that the content of the questionnaire can fairly reflect the research objectives. Based on their feedback, we further improved these items and finally identified the final version of the questionnaire (the items of original evaluation scale referred to were all in English, but the survey was conducted in China, so we invited 2 bilingual translators proficient in Chinese and English to participate in the design of the scale. One of them translated the original English scale into Chinese, and the other was responsible for proofreading to ensure accurate correspondence between the Chinese and English content). The questionnaire was mainly composed of 5-point Likert Form closed questions (1=completely not understand or not needed; $5=$ completely understand or needed).

\subsection{Statistical method}

This article uses SPSS 20.0 for data entry, statistical description, correlation analysis, reliability analysis, and validity analysis.

\section{Results}

\subsection{Sample description}

A total of 113 questionnaires were distributed in this survey, of which 102 were collected, 100 were valid, and the response rate was $90.3 \%$. According to the statistical results, the proportion of female participating in the survey was relatively high, reaching 69\%; while maleaccounted for only $31 \%$. 52\% of the respondents were in the $31-40$ age group, and only $7 \%$ were in the 
51-60 age group. In terms of educational background, the proportion of postgraduates was relatively high, reaching $52 \%$, while the proportion of university and junior college graduates was only $8 \%$. Based on the results of the respondents' answers, we divided their professional backgrounds into six categories: medical science, health management, other management, information, finance, and others. According to statistics, the proportion of respondents with a professional background of "other management"was relatively high, accounting for about $26 \%$; the proportion of "health management"was relatively low, accounting for $14.3 \%$. In addition, most of the medical management personnel participating in this survey came from the "medical business management department", accounting for about $45.7 \%$. The staff in the "science and education department" and the "logistics and general affairs department"were the least, both accounting for about $2.9 \%$. See Table 1 for details.

Table 1 Descriptive statistics of basic information of respondents

\begin{tabular}{|c|c|c|c|}
\hline Category & Variable & Frequency & Percentage \\
\hline \multirow[t]{2}{*}{ Gender } & Male & 27 & 77.1 \\
\hline & Female & 8 & 22.9 \\
\hline \multirow[t]{4}{*}{ Age } & $18-30$ & 9 & 25.7 \\
\hline & $31-40$ & 18 & 51.4 \\
\hline & $41-50$ & 7 & 20.0 \\
\hline & $51-60$ & 1 & 2.9 \\
\hline \multirow{4}{*}{ Educational level } & Doctor or above & 1 & 2.9 \\
\hline & Master & 22 & 62.9 \\
\hline & Bachelor & 11 & 31.4 \\
\hline & Junior college graduates & 1 & 2.9 \\
\hline \multirow[t]{4}{*}{ Discipline } & Others & 8 & 22.9 \\
\hline & Other management & 9 & 25.7 \\
\hline & Health management & 5 & 14.3 \\
\hline & Medical science & 13 & 37.1 \\
\hline \multirow[t]{6}{*}{ Department } & $\begin{array}{c}\text { Financial affairs } \\
\text { management department }\end{array}$ & 2 & 5.7 \\
\hline & $\begin{array}{l}\text { Logistics and general } \\
\text { affairs department }\end{array}$ & 1 & 2.9 \\
\hline & $\begin{array}{c}\text { Science and education } \\
\text { business management } \\
\text { department }\end{array}$ & 1 & 2.9 \\
\hline & Personnel department & 4 & 11.4 \\
\hline & $\begin{array}{l}\text { Medical business } \\
\text { management department }\end{array}$ & 16 & 45.7 \\
\hline & $\begin{array}{l}\text { Hospital affairs and } \\
\text { discipline inspection } \\
\text { department }\end{array}$ & 11 & 31.4 \\
\hline
\end{tabular}

\subsection{Reliability and validity of the questionnaire}

The closer the KMO test result is to 1 , the stronger the partial correlation between variables and the better the effect of factor analysis will be. When the KMO test result is greater than 0.7 , the factor analysis effect will generally be good. When the KMO test result is less than 0.5 , it is not suitable for factor analysis, Bartlett's test of sphericity is used to judge whether the correlation matrix is an identity matrix. It can be seen from Table 2 that the KMO statistic of this scale is 0.707 , which is suitable for factor analysis, the Bartlett's test rejects the null hypothesis, and all variables have strong correlation.

In the results of factor analysis, the indicators used to evaluate the validity mainly include the cumulative variance contribution rate and factor loading. The cumulative contribution rate reflects the cumulative effectiveness of the common factor on the scale or questionnaire, and the factor loading reflects the degree of correlation between the original variable and a common factor. The survey scale of this study has 4 common factors whose eigenvalues are greater than 1 , so the first 4 common factors are extracted. The cumulative variance contribution rate of the four common factors is
78.229\%, which shows that these four common factors can explain $78.229 \%$ of the variance of all variables, and the degree of explanation is good.

In this paper, the principal component method is used to extract the factors, and the varimax method is used to rotate the matrix, and the rotated component matrix is shown in Table 3. The 17 items of the teaching quality assessment survey on the special training lectures on overseas teachers'health management research are divided into 4 factors, and the questionnaire has good validity. Among them, the items 6, 7, 8, 16, 17, and 18 have a relatively high loading on the first factor, which is named "teaching ability" in this article; the items 9, 10, 11 , and 12 have a relatively high loading on the second factor, which is named "overall quality" in this article; the items 19, 20, and 21 have a relatively high loading on the third factor, which is named "posture, bearing and expression" in this article; the items 13, 14, and 15 have a relatively high loading on the fourth factor, which is named "teaching design" in this article. After analysis, the Cronbach's $\alpha$ of the subscales and the overall scale represented by each factor are all above 0.8 (teaching ability 0.904 , overall quality 0.882 , teaching design 0.892, posture, bearing and expression 0.882, total scale 
0.947), and the reliability of the questionnaire is ideal.

Table 2 Results of KMO and Barlett'stest

\begin{tabular}{lcc}
\hline Kaiser-Meyer-Olkin Measure of Sampling Adequacy (KMO) & 0.707 \\
\hline \multirow{3}{*}{ Bartlett's Test of Sphericity } & Chi-squared approximation & 534.944 \\
& Degree of freedom & 136 \\
& Significance & 0.000 \\
\hline
\end{tabular}

Table 3 Component matrix loading and factor name

\begin{tabular}{|c|c|c|c|c|c|}
\hline \multirow{2}{*}{ Factor name } & \multirow{2}{*}{ Items } & \multicolumn{4}{|c|}{ Component } \\
\hline & & 1 & 2 & 3 & 4 \\
\hline \multirow{6}{*}{$\begin{array}{l}\text { Teaching } \\
\text { ability }\end{array}$} & $7 \square$ Targeted teaching, clear thinking & 0.748 & & & \\
\hline & $\begin{array}{l}8 \square \text { Accurately grasp the key points and difficult points of the } \\
\text { courses }\end{array}$ & 0.709 & & & \\
\hline & $\begin{array}{l}6 \text { Consistent with the syllabus, informative, reflecting the frontier } \\
\text { of the subject }\end{array}$ & 0.686 & & & \\
\hline & $\begin{array}{l}18 \square \text { Skilled and effective use of modern teaching methods such as } \\
\text { multimedia }\end{array}$ & 0.674 & & & \\
\hline & $\begin{array}{l}16 \square \text { Inspiring strong, effectively mobilize the enthusiasm of the } \\
\text { students' thinking and learning }\end{array}$ & 0.656 & & & \\
\hline & $17 \square$ Teaching schedule is reasonable & 0.637 & & & \\
\hline \multirow{4}{*}{$\begin{array}{l}\text { Overall } \\
\text { quality }\end{array}$} & $\begin{array}{l}9 \square \text { Use the appropriate and effective methods and means, } \\
\text { rationally organize the teaching process }\end{array}$ & & 0.762 & & \\
\hline & $\begin{array}{l}12 \square \text { Focus on academic, informative, professional } \\
\text { and ideological penetration, service for teaching target }\end{array}$ & & 0.762 & & \\
\hline & $10 \square$ The expression is accurate, concise, clearly explained & & 0.756 & & \\
\hline & $\begin{array}{l}11 \square \text { Theory with practice, in line with the characteristics of } \\
\text { students }\end{array}$ & & 0.749 & & \\
\hline \multirow{3}{*}{$\begin{array}{l}\text { Posture, } \\
\text { bearing and } \\
\text { expression }\end{array}$} & $21 \square$ Natural teaching state, full of energy, strong affinity & & & 0.883 & \\
\hline & $\begin{array}{l}19 \square \text { The language clear, smooth, accurate and vivid; The speed of } \\
\text { rhythm is proper }\end{array}$ & & & 0.826 & \\
\hline & $\begin{array}{l}20 \square \text { Body language should be reasonable and appropriate, } \\
\text { teaching state is natural }\end{array}$ & & & 0.768 & \\
\hline \multirow{3}{*}{$\begin{array}{l}\text { Teaching } \\
\text { design }\end{array}$} & $\begin{array}{l}14 \square \text { Focus on academic, informative, professional } \\
\text { and ideological penetration, service for teaching target }\end{array}$ & & & & 0.802 \\
\hline & $\begin{array}{l}22 \square \text { Advanced teaching philosophy, style prominent, strong } \\
\text { infection, effective teaching }\end{array}$ & & & & 0.751 \\
\hline & $\begin{array}{l}13 \square \text { Reasonable arrangements for the teaching process,using } \\
\text { flexible methods, appropriate teaching design }\end{array}$ & & & & 0.680 \\
\hline
\end{tabular}

Note. Extraction method: principal component analysis; Rotation method: Varimax with Kaiser normalization; Rotation converged in ten iterations

\subsection{Score of each item and sub-scale}

As shown by Table 4 and Table5, the minimum score of items is no less than 3 , and the average score is over 4. The average score of the four sub-scales (four factors) is above 4 .

Table 4 Score of each item

\begin{tabular}{lccccc}
\hline \multicolumn{1}{c}{ Items } & $\mathrm{N}$ & Min & Max & Mean & SD \\
\hline $\begin{array}{l}\text { 6 } \square \text { Consistent with the syllabus, informative, reflecting the frontier of the } \\
\text { subject }\end{array}$ & 35 & 3 & 5 & 4.43 & 0.558 \\
$7 \square$ Targeted teaching, clear thinking & 35 & 3 & 5 & 4.66 & 0.539 \\
$\begin{array}{l}\text { 8 } \square \text { Accurately grasp the key points and difficult points of the courses } \\
9 \square \text { Use the appropriate and effective methods and means, rationally organize } \\
\text { the teaching process }\end{array}$ & 35 & 3 & 5 & 4.60 & 0.553 \\
\end{tabular}


$10 \square$ The expression is accurate, concise, clearly explained

$11 \square$ Theory with practice, in line with the characteristics of students

$12 \square$ Focus on academic, informative, professional

and ideological penetration, service for teaching target

$13 \measuredangle$ Reasonable arrangements for the teaching process, using flexible methods, appropriate teaching design

$14 \square$ Focus on academic, informative, professional

and ideological penetration, service for teaching target

$16 \square$ Inspiring strong, effectively mobilize the enthusiasm of the students'

thinking and learning

$17 \square$ Teaching schedule is reasonable

$18 \square$ Skilled and effective use of modern teaching methods such as multimedia

$19 \square$ The language clear, smooth, accurate and vivid; The speed of rhythm is proper

$20 \square$ Body language should be reasonable and appropriate, teaching state is natural

$21 \square$ Natural teaching state, full of energy, strong affinity

$22 \square$ Advanced teaching philosophy, style prominent, strong infection, effective teaching

\begin{tabular}{lllll}
35 & 3 & 5 & 4.66 & 0.539 \\
35 & 3 & 5 & 4.46 & 0.657 \\
35 & 4 & 5 & 4.57 & 0.502 \\
35 & 3 & 5 & 4.51 & 0.562 \\
35 & 3 & 5 & 4.51 & 0.612 \\
35 & 3 & 5 & 4.51 & 0.658 \\
35 & 3 & 5 & 4.54 & 0.561 \\
35 & 3 & 5 & 4.43 & 0.739 \\
35 & 3 & 5 & 4.66 & 0.539 \\
35 & 4 & 5 & 4.71 & 0.458 \\
35 & 4 & 5 & 4.77 & 0.426 \\
35 & 3 & 5 & 4.60 & 0.60 \\
\hline
\end{tabular}

Table 5 Score of each sub-scale

\begin{tabular}{cccccc}
\hline Factor Name & N & Min & Max & Mean & SD \\
\hline Teaching ability & 35 & 3.50 & 5.00 & 4.53 & 0.50 \\
Overall quality & 35 & 3.75 & 5.00 & 4.59 & 0.47 \\
Teaching design & 35 & 3.25 & 5.00 & 4.52 & 0.53 \\
Posture, bearing and expression & 35 & 3.67 & 5.00 & 4.71 & 0.43 \\
\hline
\end{tabular}

\section{Discussion}

Based on the survey results, we can see that the survey participants are mainly women, mostly in the 31-40 age group, and most of them have a master's degree or above. This result is similar to the results of the health management research ability foundation and learning needs in health management study of medical administrative personnel carried out in October 2020. The majority of the interviewees have a management background, reflecting that this training course is mainly composed of administrative personnel with a management background, and the consistency of the content of the course and the professional direction may be one of the main factors to attract them to participate in learning. In addition, through the analysis results, we know that the interviewees generally give high evaluations to overseas teachers in terms of "teaching ability", "overall quality", "teaching design", "posture, bearing and expression", reflecting the students are satisfied with the effect of the training courses. The teaching quality of the overseas teacher Professor Virginia is highly affirmed.

\section{Acknowledgement}

This article is funded by the supporting funds of the "2020-2021 International Science and Technology Cooperation Project (Famous Professors Overseas) of Department of Science and Technology of Guangdong Province" (Project Number: 2020A1414010400), and it is the research result of this project.

\section{References}

1. Z.Xu,Z.D.Yang, F.Q.Li, "One Belt And One Road" Industrial Transfer Innovation Drive Research. Macroeconomic Study, 2019(12): p 112-118. DOI: https://doi.org/ 10.16304/j.cnki.11-3952/f.2019.12.011.

2. J.M.Huang,M.S.Wang, The Impact of "One Belt And One Road" on The Medical Environment and the Strategic Impact of Management Development. Straits Science, 2017. 000(005): p 122-123.DOI: https://doi.org/ 110.3969/j.issn.1673-8683.2017.05.034.

3. J.Y.Liu, Analysis on The Problems and Countermeasures of International Cooperation in China's Medical and Health Industry Under the Strategy of "One Belt and One Road". China Chief Financial Officer, 2017. 000(009): p 39-41.DOI: https://doi.org/10.3969/j.issn.1672-576X.2017.09.01 7.

4. L.N. Ye, H.Liu, Study on Motivation of Continuing Education for Hospital Administrators in Jiangsu Province. Journal of Nanjing Medical University: Social Science edition, 2014. 04(4): p 303-303. DOI: https://doi.org/10.13768/j.cnki.cn11-3793/f.2015.563 9.

5. J.B. Li, Adapt to The New Situation to Strengthen The Study of Hospital Management. Chongqing 
Medicine, 2004. 33(9). DOI: https://doi.org/ 10.3969/j.issn.1671-8348.2004.09.001.

6. X.X. Huang, et al, Construction and Practice of Multi-level International Cooperative Teaching Model. Higher Agricultural Education, 2018(02): p41-44. DOI: https://doi.org/ 10.13839/j.cnki.hae.2018.2.009.

7. J.Q. Li, R.L. Jay, Exploration and Practice of International Talents Training in Water Conservation- Based on the Project of "Overseas Famous Teachers" of the Ministry of Education. Educatiion Modernization, 2018. 5(33): p 32-33,57. DOI:

https://doi.org/10.16541/j.cnki.2095-8420.2018.33.0 15.

8. Y.M.Lian, Exploration on the Construction of International Music Communication of Guangxi "Overseas Famous Teachers" under the Background of "One Belt And One Road". The Yellow Sound, 2017(3): p 110-111. DOI:

https://doi.org/10.3969/j.issn.1810-2980.2017.03.08 5.

9. Z, Wu., et al., Evaluation of the Health Management Research Capabilities and Learning Needs of Hospital Management Personnel. E3S Web of Conferences, 2021. 233: p. 02008. DOI: https://doi.org/10.1051/e3sconf/202123302008.

10. Z, Liu., et al., The Evaluation of Teaching Level and Exploration of Improving Ability for Young Teachers in Higher Education. Creative Education, 2015. 06(10): p. 976-981. DOI: https://doi.org/ 10.4236/ce.2015.610099. 